\title{
THE CHALLENGE OF PREPARING PRESERVICE TEACHERS TO TEACH INFORMAL INFERENTIAL REASONING
}

\author{
AISLING M. LEAVY \\ Mary Immaculate College \\ aisling.leavy@mic.ul.ie
}

\begin{abstract}
There is growing recognition of the importance of developing young students' informal inferential reasoning (IIR). This focus on informal inference in school statistics has implications for teacher education. This study reports on 26 preservice teachers utilizing Lesson Study to support a focus on the teaching of IIR in primary classrooms. Participants demonstrated proficiency reasoning about the elements fundamental to informal inferential reasoning but had difficulties developing pedagogical contexts to advance primary students' informal inferential reasoning. Specifically, issues emerged relating to data type, an excessive focus on procedures, locating opportunities for IIR, and a lack of justification and evidencebased reading. Focusing on the lesson as the unit of analysis combined with classroom-based inquiry supported the development of statistical and pedagogical knowledge.
\end{abstract}

Keywords: Statistics education research; Teacher education; Teacher knowledge

\section{INTRODUCTION}

The field of statistics education is still in its infancy. The past two decades have seen a number of developments in identifying the big ideas in statistics education. Statistics education in the elementary and middle grades, in particular, has shifted from a focus on techniques of graph construction and calculations of statistical measures to a focus on ideas such as distribution and variability. [One example of a focus on distribution is the Data About Us (Lappan, Fey, Fitzgerald, Friel \& Phillips, 2006) sixth-grade module in the Connected Mathematics Project.] A recent development in the field of statistics education is recognition of the importance of developing young students' informal inferential reasoning (IIR). A number of factors motivate the recent spotlight on informal inference. These range from the argument that current approaches to statistics in the early grades communicate an overly deterministic sense of the field of statistics which can be counteracted by a focus on informal inference and the belief that attention to informal inference may support the transition to formal inference (Zieffler, Garfield, delMas, \& Reading, 2008, p. 43). This emergence, however, of informal inference as a potential focus of study in the middle grades poses interesting questions and challenges for teachers of mathematics.

\section{THEORETICAL BACKGROUND}

\subsection{INFORMAL INFERENTIAL REASONING}

A useful definition of informal inference is "the way in which students use their informal statistical knowledge to make arguments to support inferences about unknown populations based on observed samples” (Zieffler et al., 2008, p. 44). A number of recent efforts to identify a conceptual framework for informal ideas relating to inference have been fruitful in identifying

Statistics Education Research Journal, 9(1), 46-67, http://www.stat.auckland.ac.nz/serj

C International Association for Statistical Education (IASE/ISI), May, 2010 
essential components and foundational concepts critical to informal inference. A number of useful markers of informal inferential reasoning and how it may be embodied in instructional contexts are revealed from examination of the three principles of informal inferential reasoning put forward by Makar and Rubin $(2007,2009)$ and the three basic components of informal inferential reasoning proposed by Zieffler et al. The work of these authors identifies informal inferential reasoning as involving: Generalizations that extend beyond the data, utilizing prior knowledge to the extent that the knowledge is available, providing evidence-based justifications for generalizations; and using probabilistic language in describing the generalizations while making reference to levels of certainty about the conclusions drawn.

Reading (2009), in her synthesis of research on informal inferential reasoning arising from the Fifth International Research Forum on Statistical Reasoning, Thinking, and Literacy (SRTL5 , held in 2007), identifies two categories of foundational concepts that need to be understood in order for learners to engage in the types of reasoning critical for informal inference. The first category comprises five statistical features that are central to informal inference: variation, distribution, mean, spread, and graphs. The second category consists of four statistical actions which are critical for informal inference: viewing data as an aggregate (cf. Rubin, Hammerman, \& Konold, 2006), focusing on proportions rather than absolutes (cf. Ben-Zvi, 2006), appreciating variability in samples, and appreciating randomness as a process.

\subsection{INFORMAL INFERENTIAL REASONING IN THE EARLY GRADES}

While gains have been made conceptually in terms of developing understanding of the mechanisms involved and concepts underlying informal inferential reasoning, the question of how an inference-driven approach to learning statistics can be embodied in the primary classroom remains unanswered. This section attempts to draw links between everyday data-based classroom practices prevalent in the upper primary school and the possibilities they present for leading into IIR.

Activities invoking informal inferential reasoning require learners to look beyond the data. It makes sense then, that efforts to help children look beyond the data require them to look at the data first in an effort to identify underlying patterns. The initial points of departure for IIR then, at the primary level, may differ little from the current launching of data lessons where the emphasis is on descriptive statistics. Recent recognition of the importance of reasoning about data at the primary level has placed an emphasis on the types of statistical thinking and reasoning which underpin IIR. There is ample evidence from research studies of young learners engaging in such reasoning-young learners have been shown to demonstrate relatively sophisticated reasoning when examining landmarks and trends in data distributions (Friel, Mokros, \& Russell, 1992), when reasoning about distributions (Cobb, 1999), and when focusing on variation in distributions (Cobb, 1999; Konold \& Pollatsek, 2002; Petrosino, Lehrer, \& Schauble, 2003; Watson \& Kelly, 2002). Engagement in statistical investigations is also becoming increasingly common in primary contexts. Makar and Rubin (2007) argue for the almost symbiotic interplay between inference and investigation and contend that "inference and statistical investigation cannot be separated" (p. 3). Statistical investigations, they stress, should be motivated by a compelling question, be situated within an engaging context, and produce data that are sufficiently complex so as to support reasoning and discussion. The importance of situating IIR within the context of an empirical inquiry cycle is also highlighted by Pfannkuch (2006) and many of the elements of the 4dimensional framework for statistical thinking in empirical enquiry posited by Wild and Pfannkuch (1999) are useful to inform the development of such investigations at the primary level.

Situating classroom pedagogical activities within the context of statistical investigations supports the design of activities which incorporate informal inferential reasoning. The literature identifies two forms of activities which support a focus on inference: 
(I) Using sample data to reason about characteristics of a population. Activities falling within this categorization require learners to make generalizations beyond a sample to the population (Ben-Zvi, 2006; Pratt, Johnson-Wilder, Ainley, \& Mason, 2008; Zieffler et al., 2008).

(II) Comparing samples of data to reason about possible differences between populations. These activities involve the comparison of two samples to ascertain whether differences exist followed by the generation or testing of hypotheses to account for observed differences (Makar \& Confrey, 2002; Makar \& Rubin, 2007; Pfannkuch, 2006; Watson \& Moritz, 1999).

The selection of tasks which support IIR can be further informed by the degree to which tasks require students to: utilize prior knowledge to the extent that the knowledge is available (Zieffler et al., 2008), provide evidence-based justifications for generalizations (Makar \& Rubin, 2007; Zieffler et al., 2008), and use probabilistic language in describing the generalizations while making reference to levels of certainty about the conclusions drawn (Makar \& Rubin). Figure 1 provides a framework for the design of tasks to support inferential reasoning in the primary school.

\begin{tabular}{|c|c|c|c|}
\hline $\begin{array}{l}\text { Purpose of the } \\
\text { Investigation }\end{array}$ & Action on Data & $\begin{array}{l}\text { Nature of the Statistical } \\
\text { Activity }\end{array}$ & Feature of Tasks \\
\hline $\begin{array}{l}\text { Summarize data } \rightarrow \\
\text { (descriptive statistics) }\end{array}$ & $\begin{array}{l}\text { Looking at } \\
\text { data }\end{array}$ & $\begin{array}{l}\text { Using measures of central } \\
\text { tendency and variability to } \\
\text { describe distributions }\end{array}$ & \\
\hline $\begin{array}{l}\text { Draw conclusions } \\
\text { about relationships } \\
\text { between the } \\
\text { characteristics of } \\
\text { groups of } \\
\text { observations } \\
\text { (inferential statistics) }\end{array}$ & $\begin{array}{l}\text { Looking } \\
\text { beyond the } \\
\text { data }\end{array}$ & $\begin{array}{l}\text { I. Using samples to reason } \\
\text { about populations } \\
\text { II. Comparing samples of } \\
\text { data to reason about } \\
\text { possible differences } \\
\text { between populations }\end{array}$ & $\begin{array}{l}\text { Tasks that utilize prior } \\
\text { knowledge } \\
\text { Tasks that require use } \\
\text { of evidence to support } \\
\text { generalizations } \\
\text { Tasks that draw on use } \\
\text { of probabilistic } \\
\text { language }\end{array}$ \\
\hline
\end{tabular}

Figure 1. Guiding features for design and selection of tasks to support IIR

\subsection{PREPARING TEACHERS TO TEACH INFORMAL INFERENTIAL REASONING}

Preparing teachers to teach mathematics is a complex task. The emergence of statistics as a focus of study in the primary curriculum has met with many of the same difficulties as arise in the field of mathematics education. One challenge that teachers face is the development of adequate subject matter content knowledge (Shulman, 1986) in statistics. To support the development of informal inference teachers need to be able to guide young learners in encapsulating properties of distributions and support them in differentiating signal from noise when comparing distributions or making generalizations from samples. This requires rich and interconnected understandings of statistics extending beyond the application of skills in computing means and constructing graphs. Unfortunately, there is ample evidence to indicate that preservice teachers may not possess these understandings. In many countries preservice teachers have been shown to possess little more than procedural understanding of statistical concepts consisting of having a collection of isolated rules at their disposal rather than an appropriate conceptual schema. Undergraduate students and preservice teachers have well-documented conceptual difficulties relating to concepts that underpin informal inferential reasoning: the mean (Gfeller, Niess, \& Lederman, 1999; Leavy \& 
O’Loughlin, 2006; Mevarech, 1983; Pollatsek, Lima, \& Well, 1981), median (Friel \& Bright, 1998; Groth \& Bergner, 2006), variability (Canada, 2004), and reasoning about distributions (Leavy, 2004, 2006; Makar \& Confrey, 2002).

Another challenge is the transformation of subject matter content knowledge into pedagogical content knowledge. The development of pedagogical content knowledge (Shulman, 1986) of IIR requires that teachers possess deep understandings of concepts central to statistical inference to guide them in the presentation of ideas, the anticipation of student misconceptions, and the construction of investigations and tasks that provide opportunities for the fruitful development of inferential reasoning. Makar and Rubin's (2007) presentation of classroom episodes of IIR highlight some challenges in terms of the pedagogical content knowledge necessary for the development of IIR in the primary grades, with particular reference to issues in selecting sufficiently complex data, choosing engaging contexts, and supporting children in connecting conclusions to evidence and in making predictions.

In summary, in statistics education teachers are now expected to teach content that they themselves may not have experienced as learners when they were in school. The comments of Lajoie and Romberg (1998) are particularly pertinent for the emerging area of informal inferential reasoning. The authors comment that statistical concepts may be as new a topic for teachers as for the students they teach and recommend that "teachers must be provided with appropriate preservice and in-service training that will give them the knowledge base they need to feel comfortable teaching about data and chance" (p. xv). This is exactly what this study purports to do-examine the content and pedagogical content needs of preservice teachers when teaching informal inferential reasoning at the primary level.

\section{PURPOSE AND CONTEXT OF THE STUDY}

The study examines the process involved when preservice primary teachers design and teach data lessons addressing informal inference. The study examines the obstacles faced by participants while designing and teaching data lessons and investigates the development of participants' own content and pedagogical knowledge relating to teaching (informal inferential) statistics throughout the process.

Lesson Study (Fernandez \& Yoshida, 2004; Lewis, 2002; Lewis \& Tsuchida, 1998) is used both to identify the content and pedagogical content knowledge needed for teaching informal inference and to investigate how this knowledge is used by teachers when teaching. Lesson Study is an approach for studying teaching that utilizes detailed analyses of classroom lessons. Many research methodologies used in studying teachers' understanding focus primarily on presenting teachers with isolated problems disconnected from the classroom teaching context. What these types of studies do not provide is insights into the knowledge needed for teaching-or pedagogical content knowledge needed for teaching (Shulman, 1986). Lesson study is used in this study to facilitate the examination of both the planning of lessons and the implementation of those lessons in classrooms and thus provides an avenue to explore problems of practice in statistics education.

The central activity was for participants to work collaboratively on the design and implementation of a study lesson. Participants were organized into groups of 5-6 to engage in the phases of Lesson Study. The first phase involved collaboratively planning the study lesson, this involved researching topics pertinent to the design of a lesson and the concomitant construction of a detailed lesson plan. The lesson format adhered to guidelines put forward by Ertle, Chokshi, and Fernandez (2001) and incorporated specific reference steps of the lesson (learning activities and key questions), student activities, expected student responses, teacher response to student activity/response, and goals and methods of evaluation. The implementation stage, seeing the study lesson in action, involved one preservice teacher teaching the lesson in a primary classroom while the other group members observed and evaluated classroom activity and student learning. 
Group members were then involved in the reflection and revision stages whereupon they discussed the study lesson and further revised the lesson following discussions of their classroom observations. The second implementation stage involved teaching the new version of the lesson with a second class of primary students and reflecting upon observations. The cycle concluded with in-class presentations whereupon each of the five lesson study groups shared reflections of the finalized lesson and of the lesson study process.

\section{METHOD}

\subsection{PARTICIPANTS}

The study was carried out with a group of final year Irish preservice teachers electing the teaching of mathematics as a specialist area of study during the concluding semester of their teacher education program. These preservice teachers had completed their mathematics education courses and all teaching practice requirements (at junior, middle, and senior elementary grades) and self-selected into mathematics education as a cognate area of study. The group consisted of 26 preservice teachers, all of whom were female. The mean age was 20.61 years and all had studied higher level mathematics in secondary school or received an A or upper B grade in college entrance examinations in general level mathematics. Forty percent studied mathematics in the first year of their undergraduate degree and $20 \%$ were studying mathematics to degree level. All had studied statistics and probability in secondary school and had covered pedagogical approaches to teaching data handling in their college-level mathematics education courses. Those studying mathematics to degree level had completed a course on probability and statistics in their second year of study.

\subsection{PROCEDURES}

The research was conducted over a 12 week semester, the group met twice weekly for a weekly total of four hours of contact time. The researcher was one of the instructors of the course and had primary responsibility for all instruction and supervision relating to lesson study. Participants were divided into five lesson study groups. The research design consisted of three structural components: (I) Introducing lesson study and inferential reasoning, (II) conducting lesson study, and (III) reflecting and reporting on lesson study.

During the Introducing lesson study and inferential reasoning stage, a three week period of time (12 contact hours) was dedicated to introducing participants to lesson study and inferential reasoning. The introduction to Lesson Study involved the presentation of an overview of the process, the study and critique of seminal readings relating to lesson study (e.g., Fernandez \& Yoshida, 2004; Lewis \& Tsuchida, 1998; Stigler \& Hiebert, 1999) and structured discussions arising from these components. Focused time was dedicated to exploring inferential reasoning both from a statistical standpoint and extending into pedagogical perspectives on inferential reasoning. Participants studied a number of readings specifically dedicated to informal inferential reasoning (e.g., Ben-Zvi, Gil, \& Apel, 2007; Makar \& Rubin, 2007) and discussed these in light of the Irish mathematics curriculum. This phase concluded with the researcher modeling a lesson on informal inferential reasoning. In keeping with best practices in statistics pedagogy the lesson was centered on a statistical investigation. The purpose of the investigation was to (a) model the type of statistical activity that incorporates components of statistical inference, and (b) gain insight into preservice teachers' own inferential reasoning abilities. The activity involved collecting sample data on participants' family size to make predictions about the population and then growing the sample to see the influence of increased sample size on generalizations about the population mean. 
The second stage was devoted to conducting the lesson study. This stage took place over a period of seven weeks and involved all phases of Lesson Study as outlined in previous sections of this paper. Essentially, each group met regularly to research, design, and undertake the teaching of a study lesson focusing on inferential reasoning. In each Lesson Study group, the researcher (who held the position of a "knowledgeable other"), was present at the initial planning meeting and at the final meeting prior to the teaching of the lesson. The researcher provided guidance on the design of the lesson and on aspects of informal inferential reasoning. The first lesson was taught in a local primary school to a class of upper grade children; the researcher was present for this lesson. Following this, the Lesson Study group reflected on and refined the lesson which was taught approximately 7-10 days later in a second school to children of the same class level. The researcher was present for the reflection which followed the first lesson being taught. This lesson was further refined based on reflections of the Lesson Study group.

The final stage of the research involved each group reflecting and reporting on the lesson study. This stage was centered on three primary activities: a group interview, presentation of an individual reflective paper, and a group presentation to their peers. Each group met with the researcher following the conclusion of the lesson study and discussed aspects of the process which arose during the seven weeks. Group interviews were semi-structured in nature (Fontana \& Frey, 1994) and focused on statistical and pedagogical aspects of the lesson taught in addition to issues that were specific to and arose from individual groups. A reflective assignment was produced by each participant and was guided by, but not limited to, the following components integral to the Lesson Study process: theories of teaching and learning mathematics, the development of understanding relating to inferential reasoning, and pedagogical aspects relating to the teaching of statistics. Group presentations took place over the final two weeks of semester and involved each Lesson Study group making a presentation to their peers of their Lesson Study project. Presentations provided an overview of the lesson taught, provided a critique of the lesson, identified obstacles faced in the planning for and teaching of the lesson, engaged peers in carrying our activities associated with the lessons, and displayed examples of children's work.

\subsection{DATA COLLECTION AND ANALYSIS}

The method of inquiry employed was collective case study (Stake, 1995), because the focus of the study was to provide an in-depth analysis of five cases of contemporary phenomenon (i.e., teaching) within their real-life contexts (Creswell, 1997; Yin, 2009). Each Lesson Study group constituted a case. Analysis of the data proceeded in a manner consistent with a naturalistic inquiry approach (Lincoln \& Guba, 1985). The purpose was to provide a detailed description of the process involved in designing and teaching lessons in IIR, in other words "thick descriptions" (Lincoln \& Guba, 1985), and report on the subject matter content and pedagogical content needs that arose over the course of the study.

The principal data collection technique used was participant observation. Data collection methods were synchronized closely with the stages of Lesson Study. Table 1 outlines the links between the Lesson Study cycle and the data collection process. Groups were observed during all phases of the lesson study, and the primary methods of data collection consisted of researcher observations, audio taped interviews, and written reports and responses produced by groups. Data collection procedures during step 1 , collaboratively planning the study lesson, involved recording the content of group discussions during planning meetings and the production of a log of all planning sessions held within and outside the university context. At two stages during the planning phase, each group met with the researcher to outline their lesson and discuss aspects of the lesson plan; these meetings were audio taped and transcribed. At step 2, seeing the study lesson in action, the researcher observed the teaching of the lesson in the primary school. Researcher observation notes focused particular attention on the statistical context/problem chosen to motivate the lesson, methodologies used to support student learning, models and 
manipulatives selected to illustrate statistical concepts, efforts to address misconceptions, and methods of assessment. Data collection at step 3, discussing the study lesson, involved the researcher attending the debriefing session. At this session, group members shared their thoughts on how the lesson had progressed and critiqued elements of the lesson. The outcome of step 4 was the production of a revised lesson incorporating changes and providing a justification of those changes. This new lesson was the focus of attention of step 5, teaching the new version of the lesson, involving observation on the part of the researcher of the same form that occurred in step 2. At the conclusion of the lesson study cycle, step 6, each group was interviewed about the lesson study and groups provided an in-class presentation at the end of semester, both of which were videotaped. Each participant compiled a written report outlining a detailed narrative account of their understandings of the content taught and the development of that understanding over the lesson study cycle, all lesson plans developed, a list of sources used to draft the lesson plans, and a reflective critique of what they learned about the teaching of data analysis.

Table 1: Data collection procedures as they aligned with the lesson study cycle

\begin{tabular}{|c|c|}
\hline Steps of the Lesson Study Cycle & Data Collection Structure and Method \\
\hline $\begin{array}{l}\text { Step 1: Collaboratively Planning the Study } \\
\text { Lesson }\end{array}$ & $\begin{array}{l}\text { - Audio taped meetings with researcher } \\
\text { - Written logs of group discussions } \\
\text { - Record of resources used to research and } \\
\text { design lesson }\end{array}$ \\
\hline Step 2: Seeing the Study Lesson in Action & $\begin{array}{l}\text { - Observation of lesson by researcher } \\
\text { - Observation notes of lesson study group } \\
\text { members }\end{array}$ \\
\hline Step 3: Discussing the Study Lesson & $\begin{array}{l}\text { - Audio taped group meeting of researcher and } \\
\text { lesson study participants following the lesson }\end{array}$ \\
\hline Step 4: Revising the Lesson & $\begin{array}{l}\text { - Written logs of group discussion } \\
\text { - Record of changes made to revised lesson } \\
\text { and justification of those changes }\end{array}$ \\
\hline $\begin{array}{l}\text { Step 5: Teaching the New Version of the } \\
\text { Lesson }\end{array}$ & $\begin{array}{l}\text { - Observation of lesson by researcher } \\
\text { - Observation notes of lesson study group } \\
\text { members }\end{array}$ \\
\hline $\begin{array}{l}\text { Step 6: Sharing Reflections about the New } \\
\text { Version of the Lesson }\end{array}$ & $\begin{array}{l}\text { - Written logs of group discussion } \\
\text { - Record of changes made to revised lesson } \\
\text { and justification of those changes } \\
\text { - Videotaped group presentation of their work } \\
\text { - Group interview with researcher }\end{array}$ \\
\hline
\end{tabular}

Data analysis, which was ongoing throughout the Lesson Study process, involved the identification of dominant themes and the clustering of themes into categories (Merriam, 1988). Once the initial set of themes was identified, efforts were made to validate the major categorizations by triangulation across the various data sources (teaching observations, participant self-report, group interviews, and group presentations). Identification of the pedagogical and subject-matter knowledge used when teaching was guided by use of the Knowledge Quartet Framework (Rowland, Turner, Thwaites, \& Huckstep, 2009) to categorize observations. Juxtaposing the multiple perspectives gained from observation, participant selfreport and reflection, interview, and analysis of lesson study artifacts provided rich insights into the subject matter content knowledge and pedagogical content knowledge used for teaching IIR. These insights gleaned from the analysis of the data contribute to the development of refined 
understandings of the process of statistical learning in addition to providing a focus on the development of preservice teachers and their pedagogical understandings.

\section{RESULTS}

\subsection{DATA INVESTIGATION CONTEXTS}

There were five Lesson Study groups, each of which designed a lesson on inferential reasoning. Each group was encouraged to construct authentic learning opportunities for children incorporating the process of statistical investigation. Each group devised a driving question (e.g., Makar \& Rubin, 2007) that was presented to the primary children. To arrive at a solution to the question, children engaged in a statistical investigation involving the comparison of two samples of data or the comparison of a sample to a population (see structural guidelines in Figure 1). The generated data provided an authentic context from which opportunities to engage in informal inferential reasoning were incorporated. A brief summary of the investigative contexts designed and used by each group follows:

The paperclip game (group 1) The statistical investigation focused on collecting data on the distances that individuals could blow a paperclip (cf. Friel et al., 1992). Data were collected from a population of children (the classroom children themselves) and adults (the group of five preservice teachers), and data from both groups were compared to investigate whether differences existed between the two samples. The following statement, presented to classroom children, spring-boarded the work of group 1.

Today we are going to do an experiment to investigate if we, the teachers, can blow this paperclip as far or farther than you the students. You are going to be the researchers in the investigation.

Sugar levels in cereals (group 2) This investigation involved the collation of data on the amount of sugar in everyday breakfast cereals (cf. Friel et al., 1992). Nutritional data were collected on thirty cereals that appear on the upper, middle, and lower supermarket shelves and the data sets compared to investigate whether differences in sugar levels were evident. The following problem scenario was presented to children and used to motivate the statistical investigation presented by group 2:

A friend of mine, Liam, who is the same age as you, says his favourite cereal is Frosties, but his parents are always [complaining] that he eats way too much sugar. They say that all cereals have way too much sugar. We are going to see today if they are right.

Examining name lengths (group 3) The comparison of name lengths of children in this class (cf. Lappan, Fey, Fitzgerald, Friel, \& Phillips, 2006) against the name lengths of the Munster Rugby Team constituted the main activity of this group. The activity was initiated by examination of the longest name ever recorded and also incorporated an examination of outliers in both data sets and a discussion of the impact of people of different nationalities on the shape of the graph.

When we came across this name [insert name] we thought it would be interesting to do a survey on name length. Do you think if we did a survey of the Munster rugby team's name lengths would it [name lengths] be exactly the same as ours or would it be different?

Footprint detective! (group 4) The comparison of shoe sizes of different classes of children constituted the primary activity of this lesson. The investigation was contextualized by presenting a "culprit" footprint. Children then constructed a graph of their class shoe sizes and examined this distribution relative to the culprit print in addition to examining the ways in which adding new 
data values influenced features of the data set. This distribution was then compared to a sample of children in a lower grade and comparisons drawn between samples.

I have a challenge for you. The key for the locker of the PE equipment was taken! The thief climbed on the bench to get the key. We have the footprint of the person who took the key because there were new floors being put down and there was dust everywhere - no one was allowed to wear shoes. If this had happened in the [Sports Hall] of your school, using the footprint, how would you find out who took the key?

Getting to school on time-the theme park excursion (group 5) This activity involved collecting data on the time travelled to get to school. The data set was then compared to (fictional) census data on average time taken to get to school in 1973.

Fifth [grade] class is going on a trip to Alton Towers Theme Park. Your friend is at school and has been told there are two free seats on the bus. He has taken one seat but has texted a few friends including you. The first person to arrive at school gets to go on the trip. How long will take you to get to school from your home?

\subsection{INITIAL UNDERSTANDINGS OF (INFORMAL) INFERENTIAL REASONING}

The first stage of the study, introducing Lesson Study and inferential reasoning, incorporated an in-class statistical investigation. The researcher taught a lesson which incorporated multiple components of inferential reasoning in an effort to gauge participants' own understandings of inference. The lesson involved the collection of sample data on family size and comparison of this distribution to a larger data set. The activity required the identification of patterns and trends in distributions, the use of these patterns to make predictions about the population, the comparison of two samples of unequal size, and discussion of issues relating to sampling. Participants demonstrated relatively sophisticated reasoning about samples and the limitations of making predictions from their small sample to a population. They spoke about the homogeneity of the small sample and the grown sample, and the implications for constructing a value that would represent the population data. Their descriptions of the distributions indicated the ability to make appropriate generalizations, use evidence to support assertions, and demonstrated robust understandings of variability, samples, and bias. As illustrated by the following quote, participants were familiar with this type of statistical reasoning and the sociological context of the investigation, however had not labeled this type of reasoning as inferential in nature:

Being honest I had never really heard of inferential reasoning. In the sample lesson we did in class I found I had done some of it before but it was unconsciously and I would never have been able to put a name on it. (Eleanor, group 4, final reflective paper)

Conversations conducted at the initial stages of the study revealed that, without exception, all participants spoke about their lack of exposure to and understanding of (informal) inferential reasoning prior to engaging in the study. Those studying mathematics to degree level did not draw connections with formal inference despite their study of probability and statistics in the previous semester. Generally it seemed that their lack of experience in reasoning and making inferences about distributions of data posed a challenge for many in terms of developing a working definition of informal inference. The following quote from Sarah's final reflective paper sheds light on her efforts to understand the types of data activities she had used with children prior to the study and how these activities related to informal inferential activities carried out during the initial stages. Her comments support those of Ben-Zvi (2006) in that her experiences with descriptive statistics led to the development of a deterministic lens on statistics and did not lead to opportunities to engage in inferential reasoning: 
I had not known much about or understood the topic [data handling] very well. I had thought it was based only on the data collected and represented. I had thought it was about questions like "what is the difference between the maximum and the minimum?" etc. It took a while to come to grips with the realization that basically, I was not looking beyond the data, I was looking at the data. Once I understood what I had been doing and how it fit with what I should be doing [informal inference] I felt prepared for the lesson study. (Sarah, group 4, final reflective paper)

For one group in particular, the terminology of "inferential" evoked meanings from other contexts. In the quote below we see that Sorcha's previous exposure to inference and its everyday meaning served as an obstacle for the group in developing a statistical sense of inference. The common ground between both types of inference presents a potential avenue of access for preservice teachers to draw on and develop (statistical) understandings of informal inference. Unfortunately, in this particular instance, this link was not revealed until the end of the study. As a result, multiple meanings of "inferential" posed an obstacle to developing the necessary statistical understanding.

I had come across inferential reasoning before with regard to children's ability to decipher and answer questions in English reading. I understood it as challenging the pupils to look beyond the core of the text and use a higher level of thinking to answer more abstract questions. I guess I used this understanding when we designed the first math's lesson and this lead to some problems because we didn't move it any further, we kept it too general—-we needed to make it mathematical. (Sorcha, group 5, final reflective paper)

\subsection{CHALLENGES FACED BY PRESERVICE TEACHERS WHEN PLANNING FOR AND TEACHING IIR}

Issues relating to data type The first difficulty arose when groups were focusing on designing a driving question and associated statistical investigation. When considering the suitability of statistical investigations, participants did not seem cognizant of the critical role played by data type in supporting the development of statistical reasoning. The initial investigations proposed by the groups all generated categorical data. Categorical data, as compared to quantitative data, severely limit the types of analyses that could be carried out on the data, and the degree to which inferences could be made. Participants struggled with the tension between designing investigations which would be interesting and relevant to children while simultaneously generating data whose structure was supportive of the types of reasoning critical to informal inference. This issue of selecting sufficiently complex data was also a finding of Makar and Rubin (2007) in their study of practicing teachers.

Time management issues The second issue that arose when teaching IIR was a general classroom management issue relating to time management. Four of the five groups did not succeed in completing the initial lesson within the allocated time. In three cases, groups did not have the opportunity to address inferential reasoning at all in their first lesson. In this sense, while groups provided the opportunity for children to engage in a statistical investigation, they did not meet the objective of the lesson study, informal inferential reasoning. Two factors contributed to time management issues. The first factor related to the profile of participants - they were preservice teachers with relatively little experience coordinating classroom activity around statistical investigations and had less well developed classroom management skills than a practicing classroom teacher. They were less efficient at coordinating groups of children, at managing transitions between stages of the data investigation, and coordinating classroom discussion. The second factor, excessive focus on statistical procedures, is categorized within the foundational dimension of the knowledge quartet (Rowland et al., 2009) and will be discussed in 
the next section. During the debriefing session with groups these time-related issues were discussed at length and modifications were made to subsequent versions of the lessons to address time issues. Modifications involved (a) making alterations to structures and organizational components of the lesson, and (b) removing aspects of the lesson that were not critical to moving toward inferential reasoning, for example, make data collection more efficient.

Excessive focus on procedures The extreme focus on procedures was an entirely unanticipated event in that none of the detailed planned lesson plans had allocated time for these activities. In each case the teacher drifted from the designed lesson plan in the pursuit of these emerging goals and three groups allocated large proportions of time engaging children in procedural aspects of the lesson. The disproportionate time spent on this aspect of the lesson was problematic in that it took away from time which had been located to IIR. For example, in two groups, once data were collected and graphed the teacher then engaged children in calculating means of the collected data, resulting in $25-50 \%$ of the class time being allocated to this activity. As this was not a planned activity, calculators had not been organized ahead of time and children did these calculations by hand. This focus on procedures was categorized within the foundational dimension of the knowledge quartet (Rowland et al., 2009) and relates to pre-service teachers' beliefs about the purposes of statistics. This issue was addressed in individual groups in the debriefing sessions. Interesting discussion centered on the reasons why it seemed appropriate to devote excessive amounts of time on procedural aspects of the lesson when these activities did not support the development of the lesson objective. What emerged from the discussions was that these activities were deeply ingrained in preservice teacher's experiences and beliefs about what constituted statistics as a discipline. Even though the activities were not planned, these activities seemed as natural and fitting as other unspoken norms that exist in the mathematics classroom. Groups were reminded to keep the lesson objective in mind at all times when modifying the second lesson and to consider the extent to which the classroom activities and discussions were leading them towards the goal of inferential reasoning. They were encouraged to ask themselves questions such as: Does this activity support the lesson objective? Is there a more efficient means to coordinate children in constructing graphs or in calculating measures?

Positioning of opportunities for IIR The fourth issue related to locating opportunities for inferential reasoning at the end of the lesson. In the initial lessons children were not engaged in IIR until both comparison data sets were collected. As the opportunities for inferential reasoning were located at the end of lessons, time management issues in conjunction with excessive focus on procedures meant that in many cases the lesson did not progress as far as the inferential reasoning component. Analysis of the modified (second) lesson plans highlights three different approaches that groups used to resolve this issue. Firstly, where possible, efforts were made to build in opportunities for informal inferential reasoning earlier in the lesson. This involved children closely examining the first distribution of collected data with a view to predicting how the second data set might appear. Particular attention was made to the expected positioning of landmarks, the relative size and positioning of clusters, and the expected prevalence of outliers. In concert with this, was the emphasis on children explaining their reasoning behind predictions so that predictions were based on a combination of data-based evidence from the collected data and expectations of what might emerge from the new sample. Secondly, the second lesson built in opportunities for children to construct typical values for the first set of data collected. This was manifested in questions posed to children, questions such as: Generally how long does it take children in this class to get to school (group 5)? What is the general distance a teacher can blow the paperclip (group 1)? On average, how many grams of sugar are in the top shelf cereals (group 2)? Again, responses needed to be accompanied by evidence or some form of data-based reasoning. Finally, in the rewriting of the lesson, participants were encouraged to insert expected 
length of times for each component of the lesson in an effort to provide a roadmap of the lesson and to ensure adequate time was allocated for inferential reasoning.

Lack of justification and evidence-based reasoning Observation of the initial lessons highlighted that much of the discussion in the classroom was too general and did not focus adequately on statistical reasoning. While many of the groups engaged children in conversations about the investigation and the context, at times these conversations did are not succeed in getting children to talk mathematically. In particular, when analyzing graphs, the conversation tended to focus on the context rather than the statistics. The questions, as posed in the lesson plan, had the intention of getting children to provide evidence of differences in the distribution through an examination of data landmarks and using this evidence to support assertions about differences.

Two classes of observations were made, both of which contributed to the lack of justification and evidence-based reasoning. The first class of observations related to using questions effectively to develop children's informal inference. These observations were categorized under the transformation dimension of the knowledge quartet (Rowland et al., 2009) and related to preservice teachers' poor ability to transform their own knowledge and make it accessible to children. For example, in group 3 the children were asked "Why do you think it took longer to get to school 30 years ago?" The "why" of this question was intended to direct children toward providing data-based evidence. The lesson plan had the predicted student response as "because the biggest cluster of data in 1973 is at 20-25 minutes but our biggest cluster is at $10-15$ minutes." What ensued, however, during the teaching of the lesson was a prolonged and detailed discussion on the social conditions of the time which drifted into discussion of the provision of electricity, fast cars, urban/rural issues, all of which reflected a social science lesson rather than a mathematical one and occupied $25 \%$ of the allocated time. While the discussion of context is appropriate and useful, the children's attention was not drawn back to the graph or its features.

The second class of observations were categorized within the contingency dimension of the knowledge quartet (Rowland et al., 2009) and referred to preservice teachers' struggle to deal appropriately with children's responses to activities. In group 1, one child stated that fifth class students can blow a paperclip further than teachers. The conversation immediately shifted to the generation of ideas about the "whys" of the group differences-teachers being older and less fit and so on. The error here in both groups was that the assertion was taken as true without the provision of data-based evidence. Again, there was a failure to focus children on analysis of the data, the identification of patterns, and the generation of assertions arising from those patterns. This challenge of referring to the data at hand as evidence when drawing conclusions about data has been documented with elementary children involved in statistical investigations in small groups (Hancock, Kaput, \& Goldsmith, 1992) and in classroom situations (Makar \& Rubin, 2007).

It became evident that the Lesson Study participants' own lack of familiarity with statistical investigations led to this lack of emphasis on justification and data-based evidence. This issue of the critical role of evidence in statistical reasoning was addressed during a university-based session that was scheduled after each group had taught their first lesson. Participants were given time in their Lesson Study groups to reflect on the extent to which they required children to use evidence when making assertions and discuss methods they might incorporate to provide a better focus on statistical reasoning. The following is an excerpt of the conversation that ensued in the whole class discussion:

Researcher: Would any of the groups like to share ideas you came up with to address this need to focus children on providing evidence for their assertions?

Amanda Yes, well we realized that our biggest problem was that we let children just

(group 1) shout out statements. And then other children started giving reasons and brainstorming ideas about why they could blow the paperclip further. 
Brenda Yes, so it all [the discussion] just ran away from us and I think we were so (group 1) happy that the children were excited about talking that we forgot about the statistics part of it.

Researcher: So what suggestions do you have for modifications to your second version of the lesson?

Amanda Well we are going to ask Is there a difference between the graphs?

Caroline Yes, we said the same thing ... that we just let the kids jump in too quickly. So

(group 3) we thought it would be a good idea to get the kids to work in groups to figure if the graphs are different and then find data that support their answer.

Dora We said the same thing. We would give each group a report card. On the card

(group 5) they have to list two or three reasons why statistically the graphs are different. We'd help them out by mentioning that they could look at gaps, clusters, outliers, means, modes, and so on.

Researcher: Okay. Any other ideas?

Stephanie Our group decided that if we put the graphs one above the other we could see

(group 2) the statistical differences more clearly. Once we can see the statistical differences we can then get kids to give reasons why the patterns occur.

\subsection{FACTORS WHICH SUPPORTED THE DEVELOPMENT OF INFERENTIAL REASONING}

Two factors were identified which supported the development of inferential reasoning. The first factor was the modeling of an inferential reasoning lesson at the beginning of the course. The second factor identified is how engagement in Lesson Study itself motivated the development of inferential reasoning in ways that may not have happened outside of the Lesson Study context. Structural components of the Lesson Study process provided contexts and spaces for the development of knowledge, both statistical and pedagogical.

Modelling inferential reasoning The lesson taught by the instructor at the beginning of the semester, which modeled informal inferential reasoning through comparison of a set of data on family size and its comparison with a larger data set and eventually the population mean, emerged from the data analysis as a critical activity in supporting the development of inferential reasoning. The influence of the lesson on the statistical knowledge of participants was somewhat surprising as it was designed to provide insights into participant's inferential reasoning while at the same time providing a model of how one might design a lesson on inference at the primary level. It was not a formal activity designed to focus on aspects of informal inference in any instructional or statistical sense. As revealed by participants' final reflective papers, this activity seemed extremely beneficial in developing notions of informal inference:

After our second lecture on data handling I had a much better understanding of inferential reasoning. When we discussed the graph that we made in the lecture, we all started coming up with our own theories of why the results are so, and before I knew it I was using inferential reasoning. I now understood that all it meant was "looking beyond the data." (Shona, group 1, final group presentation)

I think that the best way for us to learn ourselves about inferential reasoning was to experience it firsthand as we did. Following our lecture where we looked at family size, my understanding of inferential reasoning became more concrete and I realized it was about looking beyond the data and thinking about what the clusters, gaps, means and modes really meant in reality. (Edel, group 1 , final reflective paper) 
Focusing on children's understandings in lesson design and implementation The requirements for the Lesson Study process engaged participants in activities that supported the development of their own inferential reasoning. Specific opportunities to develop inferential reasoning were precipitated by the requirement to design and teach a lesson on inferential reasoning to primary level children and reflect on the lesson with a view to improving and reteaching the lesson.

The requirement to focus on children's understanding is a central feature of Lesson Study. The consideration and prediction of children's responses when planning the IIR lesson, and being accountable to respond to and take children's comments into consideration when refining the lesson, provided a valuable learning opportunity for preservice teachers. This emphasis on listening to children as a means to developing insights into understanding and thus feedback and inform the design of instruction is not the usual focus of teacher education at this stage of their careers. As can be seen from the following quotes this focus on children's IIR and the attention to questions posed by children motivated the development of participants' own statistical understanding:

When I taught the first lesson my understanding developed further as the children came up with some reasons that we didn't even think of when writing the lesson plan. Teaching the first lesson was a good way of finding out the children's point of view on inferential reasoning and then from there thinking a little more about my own understanding. (Edel Group 1, final reflective paper)

When we sat down to write the first lesson plan, my knowledge of inferential reasoning began to become clear as we had to think up of questions to ask the children. We also had to think of the children's possible responses to our questions. (Anna, group 3, final reflective paper)

One child contributed a very interesting suggestion which got us thinking. If one range goes from 1-4 and therefore the range is 3 and the other data's range goes from 3-6 and is also 3 . Can it be said that these two sets have the same range? After much discussion we concluded that yes it can be said that the ranges were the same. (Eleanor, group 4, commenting on lesson 1 de-briefing session)

Observation of the study lesson The requirement to engage in observation of the study lesson followed by reflection on the lesson provided participants the opportunity to learn from mistakes and develop opportunities for inferential reasoning in the second lesson. The opportunity to observe lessons provides a valuable learning opportunity for the observer (Rowland et al., 2009). Much of the development of understanding of IIR and pedagogical approaches to teaching IIR came about by observing the lesson and reflecting on events that occurred within the lesson study. Here we saw preservice teachers adopt some of the attributes of reflective practitioners and begin to reflect on action (Schön, 1983). For many of the groups, the reflections on the first lesson highlighted the need to introduce new approaches and concepts which would direct children towards reasoning inferentially. Arriving at a solution to the problem and identifying approaches, in this case reference to typicality, motivated participants' own development of understanding of IIR:

After meeting with our group following the first lesson we realized there was a lot more opportunities for inferential reasoning throughout the lesson. I think this is when my concept of inferential reasoning broadened, especially when I was introduced to the concept of typical values. We needed to think of a way to get children to identify a pattern in the data and move away from focusing on their own individual data values. So, along with our mentor, we decided to get them to identify typical values. Again this was a new concept to me. I learned that getting children to construct typical values would be very effective in inferential reasoning and also in interpreting data and it made things clearer for me. (Dora, group 5, final reflective paper) 
Reflection and modification of aspects of the study lesson Reflecting on the lesson also identified the need to design questions to support the development of children's informal inferential reasoning. A common finding from reflection on the first teaching episode was that the questions posed to the children did not adequately support inferential reasoning. Participants identified the need to construct open-ended questions that facilitated discussion while at the same time incorporating sufficient structure so as to point children towards inferential reasoning. These criteria motivated participants to discuss exactly what their own inferences were about the data, identify the reasonableness of these inferences, and determine ways that they may structure the activity and tasks so as to guide children to examining the data inferentially. The second lesson provided the opportunity to test these new strategies and experience success in supporting the development of IIR in the classroom:

In the first lesson inferential reasoning was still a new idea and we focused on yes or no questions and had forgotten about the "why" ... In the second lesson we got the children to talk about the data in groups and we wrote our questions more carefully. This way all the children had a say and their ideas could be heard. One comment I heard was "The biggest/mode in the teachers is smaller than ours because they had to blow 12 times and we only blew twice, I think if they were to blow again only twice theirs might be bigger." And this was contradicted by "No ours will still be bigger because our x's go out further on the graph." I think the changes in the second lesson were a great way to get children talking and looking beyond the data, and also showed us that we were getting them to reason inferentially. (Dora, group 5, final group presentation)

I have learned the important role a teacher's carefully focused questioning plays in allowing children to become part of inferential reasoning rather than merely focus on the mastery of procedures or methods. (Deirdre, group 5, final group interview)

In the second lesson, we were much smarter, this time we strategically created open ended and provocative questions to stimulate inferential reasoning and mathematical discourse. (Sarah, group 4, final reflective paper)

Reflecting on the lesson highlighted the need to emphasize mathematical justification and data-based reasoning. Following analysis of the first lesson, participants realized that they had little evidence to indicate that children were reasoning inferentially. One of the reasons to account for this was that participants had not themselves identified what constituted evidence for inferential reasoning. In several groups children were asked questions that did not require them to justify their conclusions about data. These preservice teachers identified the need to provide greater focus on getting children to reason about and discuss data by using data-based reasoning:

As our inferential questions in the first lesson were mostly based on assumptions about facts outside of the data, we neglected to challenge the children to infer information from one set to another. In short, the questions we asked were not allowing the children to think statistically. (Patricia, group 4, final group presentation)

The significance of open ended, focused and sequential questions in the assignment has absolutely taught me to look at maths teaching in a different light. I would now be so much more aware of asking the children to give reasons for their answers (whether correct or incorrect) and asking them to explain why they think this. (Deirdre, group 5, final reflective paper)

Finally, reflecting on the lesson led to an analysis of the time allocated to all aspects of the lesson. Analysis of the lessons highlighted that a large proportion of time spent in the first lessons was on procedural and algorithmic aspects of the statistics (for example, calculation of means). Despite this focus not being evident in the lesson plans, teachers "slipped" into the mode of teaching algorithms. As many of the groups had end-loaded the inferential reasoning components 
of the lesson, the time dedicated to procedures resulted in them not being able to complete the lesson-and thus not engaging students in inferential reasoning:

I found the lesson study to be a very useful exercise in analyzing how exactly you spend the minutes of the lesson. In our first lesson, almost 20 minutes was devoted to finding the mean. But, finding the mean wasn't an objective of the lesson, or written into the plan-but we spent over one third of the time on just calculating it. Reflecting on the lesson makes you think about the decisions you made and whether they helped us meet our objectives. (Shona, group 1, final group presentation)

The objective was to get children talking about the data and its shape and using this to draw conclusions. For this reason, computations were kept to a minimum. A good inferential reasoning class will have the children discussing the data and not working out averages. (Edel, group 1, final group presentation)

\subsection{CONCLUDING UNDERSTANDINGS}

At the conclusion of the study, participants outlined their understanding of IIR and described the difficulties and tensions they encountered when developing their own understandings of inferential reasoning. Understandings were still in flux and under development at the end of the study; however participants seemed to have a strong sense of the underpinnings of IIR and of pedagogical approaches to support the development of student understanding.

I still don't feel completely confident in my understanding of inferential reasoning. I am sure there is a lot more to learn about it. However, it seems to me that inferential reasoning is where we look at a set of data and from this data we can make assumptions, draw conclusions and make predictions from this data. (Eleanor, group 4, final reflective paper)

My understanding developed slowly ... I spent quite a while talking about it at meetings and looking it up in books and on the internet which left me with my current understandings. Things may appear to occur randomly but when observed carefully and compared with other groups you can look at certain patterns found in them and make inferences about what you are studying or give suggested reasons for what you see. When you make these conclusions you are reasoning inferentially. (Leah, group 2, final reflective paper)

Several participants referred to the tension between making predictions and generalizations that extend beyond the data while at the same time feeling the need to ground these generalizations within the data at hand. While participants were able to coordinate both aspects in their own practice in the early stages of the study, for some participants "unpacking” (Ma, 1999) this knowledge was a challenge.

I began to get a better idea of what was expected (when teaching IIR) and realized that although you were looking beyond the data you still had to keep referring back to the statistics in order to fully achieve inferential reasoning. (Tina, group 2, final reflective paper)

Finally the theme that emerged strongest at the end of the study was the development of statistical reasoning as a result of engaging in the statistical investigations. Participants referred to their new confidence in reasoning with statistical ideas and improved ability in making sense of statistical information. They spoke of their newfound ability to make interpretations based on comparisons of data; the most frequently mentioned improvement was in relation to interpretation based on statistical summaries of data. The statistical investigations, and driving questions that were central to the study, served as the catalyst for developing understanding of statistical measures and their use in authentic contexts. 
I was quite confident at the start that I knew exactly what was involved when it came to working out statistics. I knew how to find the mean, range, mode, median and what an outlier was. What I didn't realize is that knowing the why of calculating these is just as important as knowing the how. ... It is really important that we know why we are finding the mean, median and mode etc. and almost useless if we can just use equations that we have "learned off" to work these out without any reason or basis for it. This was an aspect we had trouble with in designing the first lesson as we were just asking the pupils to work out the statistics of the data rather than giving them a reason as to why they should work it out. (Anna, group 3, final reflective paper)

When I thought about data previously I felt the most important piece was constructing the data representation-I thought that data analysis was just something you did at the end of the lesson to wrap up the lesson for a few minutes_-something vague that required asking a few questions on the data. I now feel that data analysis is just as important as constructing the data representation-I feel I could spend many lessons just on analyzing a data set alone now. I now firmly believe that children learn most through exploration and not just through the learning of formulas and rules. I had heard this all the time in maths education lectures but I guess I just wasn't convinced until I saw it happening in our own classroom. (Sorcha, group 5, final reflective paper)

\section{SUMMARY AND CONCLUSIONS}

The goal of this study was to examine the obstacles faced by preservice teachers when designing and teaching informal inference and to investigate the development of participants' own content and pedagogical knowledge relating to teaching (informal inferential) statistics throughout the process. In keeping with other studies examining subject matter content knowledge (Friel \& Bright, 1998; Groth \& Bergner, 2006), some content knowledge difficulties relating to descriptive statistics, the median and graph knowledge, were identified. Content knowledge difficulties, in the context of this study, were swiftly identified and addressed by participants themselves during their efforts to prepare for Lesson Study and did not pose an obstacle to teaching mathematics. In this sense, Lesson Study served as a vehicle to uncover and in turn tackle content knowledge difficulties that arose.

It was not expected that preservice teachers would hold deeply sophisticated or complex understandings of inferential reasoning. While they had not been exposed to inferential reasoning prior to engaging in the study, they had developed skills in generating descriptive statistics. These descriptive statistics, which may be considered as building blocks upon which later inferential activities are based, are critical for providing evidence which informs decisions and judgments central to informal inferential reasoning. Nevertheless, preservice teachers demonstrated proficiency in reasoning about many of the elements fundamental to informal inferential reasoning. The outcomes of the exercise in informal inferential reasoning carried out at the initial stages of the study provided evidence of an aggregate view of data (Rubin et al., 2006) and the concomitant ability to reason about signals and noise (Konold \& Pollatsek, 2002). Furthermore, participants provided conjectures to explain variability (Rubin et al.) and made generalizations which extended beyond the data (Makar \& Rubin, 2007; Pfannkuch, 2006; Rossman, 2008). These generalizations were presented in conjunction with data-based evidence and took into account issues of sample size. This relatively sophisticated statistical reasoning demonstrated at the beginning of the study, while not anticipated, was not altogether surprising given the high academic profiles of entry-level Irish preservice teachers (Wall, 2001).

What was unexpected, particularly following their evidenced ability to reason inferentially, were the difficulties preservice teachers encountered in developing pedagogical contexts which would advance the informal inferential reasoning of primary level students. Hence it was pedagogical content knowledge (Shulman, 1986) that presented the greatest challenge for preservice teachers over the course of the study, and difficulties with pedagogical content knowledge manifested themselves across all Lesson Study groups. Given the limited teaching 
experiences of these preservice teachers, we expect pedagogical content knowledge to be under development. What is interesting about this study is that participants demonstrated relatively strong subject matter content knowledge, however demonstrated difficulty transforming this knowledge into pedagogical content knowledge. Ball, Hill, and Bass (2005) refer to the knowledge preservice teachers exhibited as common content knowledge and classify the difficulties which arose as falling into the realm of specialized content knowledge. Specialized content knowledge is the knowledge that teachers are expected to have. The insights generated into the pedagogical content knowledge difficulties of these participants provide valuable information regarding the needs of early career teachers as they prepare to teach informal inferential reasoning.

As mentioned in the Results section, a number of difficulties arose for preservice teachers in their planning for and teaching of informal inference. Two problems arose relating to participants' foundational understandings (Rowland et al., 2009) of statistics. The first was an overt subject knowledge difficulty which related to data structure and the role played by data in supporting the types of inferential reasoning required. The second related to beliefs about the purpose of statistics as a discipline and was evident in the tendency to engage students in statistical procedures unrelated to the lesson objective. General pedagogical difficulties also were evident in time management aspects of the lesson. The difficulty associated with supporting children in connecting conclusions to evidence and in making predictions arose from issues categorized in the transformational and contingency dimensions of the knowledge quartet (Rowland et al.). The time management difficulties and aforementioned difficulty with using data-based evidence to support assertions were also related to participants' lack of experience with statistical investigations both as learners and teachers. For example, while participants themselves demonstrated the ability to use evidence-based reasoning in their own statistical investigation in the initial stage of the study, and children in classrooms did not demonstrate difficulty in using data-based evidence when they were explicitly asked for this evidence, what emerged was that preservice teachers themselves were not aware of the importance of this aspect of statistical thinking within the process of statistical investigation.

This difficulty of viewing data as evidence was a finding arising from Makar and Rubin's 2007 study. However in the aforementioned study the issue arose with the children using the data they had as evidence for making predictions. One reason to account for the difference in ability to use data as evidence across both studies may be the role of experience- the teachers in Makar and Rubin's study were practicing teachers with experience in teaching statistics as compared to the preservice teachers in the present study. It became evident in this study that the primary problem was preservice teachers' lack of experience engaging in statistical investigative cycles themselves as learners. They were unaware of the elements critical to statistical thinking and as such needed to be provided with signposts of what to focus on statistically when engaging children in investigative activities. Their own experiences of school statistics as focusing on tools and artifacts rather than on statistical processes and contexts resulted in them constructing graphs without knowing why they were doing so and finding averages without understanding what the outcomes communicated about data-reflecting an emphasis on doing statistics rather than being informed consumers of statistics (Gal \& Garfield, 1997). This left them unprepared and in some ways disoriented when trying to navigate children through statistical investigations. The types of thinking and dispositions critical to statistical problem solving are outlined by Wild and Pfannkuch (1999) and within their four-dimensional framework they specifically mention recognition of need for data (p. 226) as a type of thinking foundational to statistical thinking. This form of statistical thinking is integral to the investigative cycle of data-based enquiry, experiences which participants themselves did not have as statistical learners.

Thus the move in this study to process-oriented approaches to learning statistics represented a fundamental shift in perspective for participants. The holistic and process-oriented approach of teaching IIR embedded within the context of a statistical investigation represented a stark contrast 
to their previous experiences of teaching and learning statistics. The activity of making inferences from real data required a conceptual shift from viewing the generation of descriptive statistics (and the construction of graphs) as the end points of instruction to thinking about them as tools for meaning making and evidence gathering. These measures, which had previously been viewed as little more than techniques, now assumed the role of functional tools in the search for patterns in data and in the search for understanding of underlying phenomena.

This study provides further support of what we already know-content knowledge is necessary but not sufficient to teach. Those preservice teachers studying mathematics to degree level did not demonstrate greater insight into the inference components of the lesson as demonstrated by conversations during the group planning meetings and in those individuals' reflective reports. This finding is in keeping with research which now questions the once widely held belief that knowledge of the subject is the primary factor influencing teacher effectiveness (Begle, 1979; Borko et al., 1992). It would seem that formal qualifications in mathematics are not directly related to the mathematics that preservice teachers teach. Teachers in this study who studied mathematics to degree level did not demonstrate profound understandings of fundamental mathematics (Ma, 1999) of the kind that are fundamental to teaching at primary level. It is this form of specialized content knowledge, also referred to as mathematical knowledge for teaching, that has been found to result in better mathematics teaching (Hill et al., 2008) and have better outcomes for students in classrooms (Hill, Rowan, \& Ball, 2005). This finding highlights the need to re-examine the content of the mathematics courses that elementary preservice teachers study and underscores the necessity to make closer connections with this mathematics and the mathematics they teach. The focus of many studies in the field of mathematics education has been on the problem of content knowledge difficulties and the impact this has on teaching. What this study reveals is that even in the presence of demonstrable content knowledge understandings, the translation of this knowledge into forms amenable for use in pedagogical contexts is a complex, arduous, and difficult task.

Recent research on informal inference has provided important insights into foundational concepts and principles of informal inference. We are now at a critical departure point in relation to bridging the divide between theory and practice. There is a pressing need for research that examines the potential role that IIR can play in primary level statistics education both in terms of it as a vehicle to support statistical reasoning and as a means to lay the foundations for formal inference. Secondly, emphasis needs to be placed on identifying tasks and pedagogical contexts that support children in developing rich and robust understandings of inference.

In conclusion, the focus of this study was to support preservice teachers in developing understanding of informal inferential reasoning as it applies in primary contexts. However, what emerged from the data was the extraordinary opportunity that IIR provided as an avenue for deepening understanding of statistical processes. The statistical investigations that were carried out as the context for embedding IIR served as a mechanism for changing perceptions of statistics and forming the "bridge” (Ben-Zvi et al., 2007) between exploratory data analysis and statistical inference.

\section{REFERENCES}

Ball, D. L., Hill, H. H., \& Bass, H. (2005). Knowing mathematics for teaching: Who knows mathematics well enough to teach third grade, and how can we decide? American Educator, 29(1), 14-17, 20-22, 43-46.

Begle, E. G. (1979). Critical variables in mathematics education: Findings from a survey of the empirical literature. Washington, D.C.: Mathematical Association of America and National Council of Teachers of Mathematics.

Ben-Zvi, D. (2006). Scaffolding students' informal inference and argumentation. In A. Rossman \& B. Chance (Eds.), Working cooperatively in statistics education: Proceedings of the 
Seventh International Conference on Teaching Statistics, Salvador, Brazil. [CDROM]. Voorburg, The Netherlands

Ben-Zvi, D., Gil, E., \& Apel, N. (2007, July). What is hidden beyond the data? Helping young students to reason and argue about some wider universe. Paper presented at Fifth International Research Forum on Statistical Reasoning, Thinking, and Literacy (SRTL-5), University of Warwick, UK.

Borko, H., Eisenhart, M., Brown, C. A., Underhill, R. G., Jones, D., \& Agard, P. C. (1992). Learning to teach hard mathematics: Do novice teachers and their instructors give up too easily? Journal for Research in Mathematics Education, 23(3), 194-222.

Canada, D. (2004). Preservice teachers' understanding of variation. Unpublished doctoral dissertation, Portland State University.

[Online: www.stat.auckland.ac.nz/ iase/publications/dissertations/dissertations.php]

Cobb, P. (1999). Individual and collective mathematical development: The case of statistical data analysis. Mathematical Thinking and Learning, 1(1), 5-43.

Creswell, J. W. (1997). Qualitative inquiry and research designs: Choosing among five traditions. Thousand Oaks, CA: Sage.

Ertle, B., Chokshi, S., \& Fernandez, C. (2001). Lesson planning tool. Retrieved June 08, 2009, from http://www.tc.columbia.edu/lessonstudy/doc/Lesson_Planning_Tool.pdf.

Fernandez, C., \& Yoshida, M. (2004). Lesson study. A Japanese approach to improving mathematics teaching and learning. : Mahwah, NJ: Lawrence Erlbaum Associates..

Fontana, A., \& Frey, J. (1994). Interviewing: The art of science. In N. K. Denzin and Y. S. Lincoln (Eds.), Handbook of qualitative research (pp. 361-376). Thousand Oaks, CA: Sage Publications.

Friel, S. N., \& Bright, G. W. (1998). Teach-Stat: A model for professional development in data analysis and statistics for teachers K-6. In S. P. Lajoie (Ed.), Reflections on statistics: Learning, teaching, and assessment in grades K-12 (pp. 299-316). Mahwah, NJ: Lawrence Erlbaum Associates.

Friel, S. N., Mokros, J. R., \& Russell, S. J. (1992). Used numbers. Statistics: Middles, means, and in-betweens. Palo Alto, CA: Dale Seymour Publications.

Gal, I., \& Garfield, J. (Eds.). (1997). The assessment challenge in statistics education. Amsterdam: IOS Press and the International Statistical Institute.

Gfeller, M. K., Niess, M. L., \& Lederman, N. G. (1999). Preservice teachers' use of multiple representations in solving arithmetic mean problems. School Science and Mathematics, 99(5), 250-257.

Groth, R. E., \& Bergner, J. A. (2006). Preservice elementary teachers' conceptual and procedural knowledge of mean, median, and mode. Mathematical Thinking and Learning, 8(1), 37-63.

Hancock, C., Kaput, J. J., \& Goldsmith, L. T. (1992). Authentic inquiry with data: Critical barriers to classroom implementation. Educational Psychologist, 27(3), 337-364.

Hill, H. C., Blunk, M. L., Charalambous, C. Y., Lewis, J., Phelps, G. C., Sleep, L., \& Ball, D. L. (2008). Mathematical knowledge for teaching and the mathematical quality of instruction: An exploratory study. Cognition and Instruction, 26(4), 430-511.

Hill, H. C., Rowan, B., \& Ball, D. L. (2005). Effects of teachers' mathematics knowledge for teaching on student achievement. American Educational Research Journal, 42(2), 371-406.

Konold, C., \& Pollatsek, A. (2002). Data analysis as the search for signals in noisy processes. Journal for Research in Mathematics Education, 33(4), 259-289.

Lajoie, S. P., \& Romberg, T. A. (1998). Identifying an agenda for statistics instruction and assessment in K-12. In S. P. Lajoie (Ed.), Reflections on statistics: Learning, teaching, and assessment in grades K-12 (pp. vii-xxi). Mahwah, NJ: Lawrence Erlbaum Associates.

Lappan, G., Fey, J., Fitzgerald, W., Friel, S., \& Phillips, E. (1996). Data about us. Boston, MA: Pearson Prentice Hall. 
Leavy, A. M. (2004). Indexing distributions of data: Preservice teachers' notions of representativeness. School Science and Mathematics, 104(3), 119-134.

Leavy, A. M. (2006). Using data comparison to support a focus on distribution: Examining preservice teacher's understandings of distribution when engaged in statistical inquiry. Statistics Education Research Journal, 5(2), 89-114. [Online: http://www.stat.auckland.ac.nz/ iase/serj/SERJ5(2)_Leavy.pdf]

Leavy, A. M. \& O’Loughlin, N. (2006) Moving beyond the arithmetic average: Preservice teachers understanding of the mean. Journal of Mathematics Teacher Education, 9(1), 53-90.

Lewis, C. (2002). Lesson study: A handbook of teacher-led instructional improvement. Philadelphia, PA: Research for Better Schools.

Lewis, C., \& Tsuchida, I. (1998). A lesson is like a swiftly flowing river: How research lessons improve Japanese education. American Educator, 22(4), 12-17, 50-52.

Lincoln, Y. S., \& Guba, E. G. (1985). Naturalistic inquiry. Newbury Park, CA: Sage Publications.

Ma, L. (1999). Knowing and teaching elementary mathematics: Teachers' understanding of fundamental mathematics in China and the United States. Mahwah, NJ: Lawrence Erlbaum Associates.

Makar, K., \& Confrey, J. (2002). Comparing two distributions: Investigating secondary teachers' statistical thinking. In B. Phillips (Ed.), Proceedings of the Sixth International Conference on Teaching Statistics: Developing a statistically literate society, Cape Town, South Africa. [CD-ROM]. Voorburg, The Netherlands: International Statistical Institute.

[Online: http://www.stat.auckland.ac.nz/ iase/publications/1/10_18_ma.pdf]

Makar, K., \& Rubin, A. (2007, July). Beyond the bar graph: Primary teachers' uses of informal inference to teach statistical inquiry. Paper presented at Fifth International Research Forum on Statistical Reasoning, Thinking, and Literacy (SRTL-5), University of Warwick, UK.

Makar, K., \& Rubin, A. (2009). A framework for thinking about informal statistical inference. Statistics Education Research Journal, 8(1), 82-105.

[Online: http://www.stat.auckland.ac.nz/ iase/serj/SERJ8(1)_Makar_Rubin.pdf]

Merriam, S. B. (1988). Case study research in education: A qualitative approach. San Francisco: Jossey-Bass.

Mevarech, Z. R. (1983). A deep structure model of students' statistical misconceptions. Educational Studies in Mathematics, 14(4), 415-429.

Petrosino, A. J., Lehrer, R., \& Schauble, L. (2003). Structuring error and experimental variation as distribution in the fourth grade. Mathematical Thinking and Learning, 5(2\&3), 131-156.

Pfannkuch, M. (2006). Informal inferential reasoning. In A. Rossman \& B. Chance (Eds.), Working cooperatively in statistics education: Proceedings of the Seventh International Conference on Teaching Statistics, Salvador, Brazil. [CDROM]. Voorburg, The Netherlands [Online: http://www.stat.auckland.ac.nz/ iase/publications/17/6A2_PFAN.pdf]

Pollatsek, S. J., Lima, S., \& Well, A. D. (1981). Concept or understanding: Students' understanding of the mean. Educational Studies in Mathematics, 12, 191-204.

Pratt, D., Johnston-Wilder, P., Ainley, J., \& Mason, J. (2008). Local and global thinking in statistical inference. Statistics Education Research Journal, 7(2), 107-129.

[Online: http://www.stat.auckland.ac.nz/ iase/serj/SERJ7(2)_Pratt.pdf]

Reading. C. (2009, August). Cognitive development of informal inferential reasoning. Paper presented at the $57^{\text {th }}$ Session of the International Statistical Institute (ISI-57), Durban, South Africa.

Rossman, A. J. (2008). Reasoning about informal statistical inference: one statistician's view. Statistics Education Research Journal, 7(2), 5-19.

[Online: http://www.stat.auckland.ac.nz/ iase/serj/SERJ7(2)_Rossman.pdf]

Rowland, T., Turner, F., Thwaites, A., \& Huckstep, P. (2009). Developing primary mathematics teaching. London: Sage. 
Rubin, A., Hammerman, J. K. L, \& Konold, C. (2006). Exploring informal inference with interactive visualization software. In A. Rossman \& B. Chance (Eds.), Working cooperatively in statistics education: Proceedings of the Seventh International Conference on Teaching Statistics, Salvador, Brazil. [CDROM]. Voorburg, The Netherlands

Schön, D. A. (1983). The reflective practitioner: How professionals think in action. London: Temple Smith.

Shulman, L. S. (1986). Those who understand: Knowledge growth in teaching. Educational Researcher, 15(2), 4-14.

Stake, R. E. (1995). The art of case study research. Thousand Oaks, CA: Sage Publications.

Stigler, J. W., \& Hiebert, J. (1999). The teaching gap. New York: Free Press.

Wall, E. (2001). A study of the mathematical content knowledge of primary teacher education students. Unpublished doctoral dissertation, University College Dublin.

Watson, J. M., \& Kelly, B. A. (2002). Statistics education at the school level: Can grade 3 students learn about variation? In A. Rossman \& B. Chance (Eds.), Working cooperatively in statistics education: Proceedings of the Seventh International Conference on Teaching Statistics, Salvador, Brazil. [CDROM]. Voorburg, The Netherlands [Online: http://www.stat.auckland.ac.nz/ iase/publications/1/2a1_wats.pdf]

Watson, J. M., \& Moritz, J. B. (1999). The beginning of statistical inference: Comparing two data sets. Educational Studies in Mathematics, 37(2), 145-168.

Wild, C. J., \& Pfannkuch, M. (1999). Statistical thinking in empirical inquiry. International Statistical Review, 67(3), 223-265.

Yin, R. K. (2009). Case study research: Design and methods (4th ed.). Newbury Park, CA: Sage Publications.

Zieffler, A., Garfield, J., delMas, R., \& Reading, C. (2008). A framework to support research on informal inferential reasoning. Statistics Education Research Journal, 7(2), 40-58.

[Online: http://www.stat.auckland.ac.nz/ iase/serj/SERJ7(2)_Zieffler.pdf]

AISLING M. LEAVY

Department of Language and Mathematics Education

R124 Mary Immaculate College

South Circular Road

Limerick, Ireland

061204978 